\title{
Assessing Temporal Characteristics of Meteorological Drought Trends in the Anantapuramu District, Andhra Pradesh
}

\author{
D. Uma Bai ${ }^{1}$, B. Sarojini Devi ${ }^{2}$, H.V. Hema Kumar ${ }^{3}$ and P. Sumathi ${ }^{4}$ \\ ${ }^{1}$ Department of SWE, College of Agricultural Engineering, Bapatla, 522101, India \\ ${ }^{2}$ College of Agricultural Engineering, Madakasira, 515301, India \\ ${ }^{3}$ Department of Soil and Water Conservation Engineering, CAE, Bapatla-522101, India \\ ${ }^{4}$ Department of Statistics and Mathematics, CAE, Madakasira, India \\ *Corresponding author
}

\section{A B S T R A C T}

\begin{tabular}{|l|}
\hline K e y w o r d s \\
$\begin{array}{l}\text { Standardized precipitation } \\
\text { index, Meteorological } \\
\text { drought, Analysis of } \\
\text { drought occurrences } \\
\text { categorise, Drought } \\
\text { severity }\end{array}$ \\
\hline Article Info \\
\hline $\begin{array}{l}\text { Accepted: } \\
\text { 10 July 2018 } \\
\text { Available Online: } \\
\text { 10 August } 2018\end{array}$ \\
\hline
\end{tabular}

\section{Introduction}

Drought is one of the major environmental disasters, which have been occurring in almost all climatic zones and damage to the environment and economies of several countries has been extensive. Drought damages are more pronounced or prominent in areas where there is a direct threat to livelihoods. In drought management, making the transition from crisis to risk management is difficult because little has been done to understand and address the risks associated with drought. Droughts are occurring in different regions of the world with increased frequency and severity. In India, large parts of the country perennially reel under recurring drought. Over $68 \%$ of the total area is vulnerable to drought. The 'chronically drought-prone areas' is around $33 \%$ and receive less than $750 \mathrm{~mm}$ of rainfall, while $35 \%$, classified as 'drought-prone' receive rainfall of $750-1,125 \mathrm{~mm}$. The major drought years in India were 1877, 1899, 1918, 1972, 1987 and 2002. There are a number of classifications for drought. One of the classifications is according to its physical aspects namely, Meteorological, Hydrological 
and Agricultural. According to the India Meteorological Department (IMD), meteorological drought occurs when the seasonal rainfall received over an area is less than $75 \%$ of its long-term average value. If the rainfall deficit is between $26-50 \%$, the drought is classified as 'moderate', and 'severe' if the deficit exceeds 50\%. Agricultural drought occurs when there is insufficient soil moisture to meet the needs of a particular crop at a particular point in time. Hydrological drought is a deficiency in surface and sub-surface water supply. It is measured as stream flows and also as lake, reservoir and groundwater levels. The problems of drought-prone regions in India vary in magnitude, temporally and spatially. Hence drought risk assessment is the necessity to cope up with this devastating drought which affects the society a lot.

Drought indices are one of the very important tools to monitor and to assess drought, because they simplify complex interrelationships between many climate parameters. There is extensive literature on the quantification of drought by using various indices, models and water balance simulations. Precipitation has been used to develop a variety of indices, because it is a key variable to study meteorological drought. Among the meteorological indices, the Palmer Drought Severity Index (PDSI) and Standardized Precipitation Index (SPI) are more commonly used. The SPI has certain advantages over others such as use of rainfall data alone and also its variable time scale, which allows it to describe drought conditions important for a range of meteorological, hydrological and agricultural applications.

The impact of rainfall deficiency on water resources varies markedly on a temporal scale for different water storage components of the hydrologic system. While soil moisture responds to precipitation anomalies on a relatively short scale, groundwater, stream flow, and reservoir storage reflect longer-term precipitation anomalies. McKee (1993) in developed the Standardized Precipitation Index (SPI) to quantify the precipitation deficit for multiple time scales, reflecting the impact of precipitation deficiency on the availability of various water supplies. They calculated the SPI for 3, 6, 12, 24, and 48 month scales to reflect the temporal behaviour of the impact.

Several studies used SPI for real time monitoring and analysis of drought. SPI was applied to monitor the intensity and spatial extension of droughts at different time scales in South Africa. Drought severity and its characteristic in Thessaly region, Greece, were examined using SPI and the in Thessaly region. SPI was used by to map the spatial extents of drought hazards in different time steps for western part of Bangladesh. Yildiz (2009) determined the characteristics of meteorological droughts in the Hirfanli Dam Basin, a semi-arid region in Turkey using SPI as a measure for drought severity. Gupta $e t$ al., (2010) carried out a study on temporal and spatial analyses of meteorological drought using SPI and hydrological drought based on theory of runs. In this paper an attempt has been made using to analyze spatial pattern of meteorological drought using SPI which can examine the characteristic of drought and can give an indication of drought at various levels of severity.

\section{Study area}

Anantapuramu district is one of the four districts of Rayalaseema Region and the largest in area among the 13 districts of Andhra Pradesh. The district is economically backward and chronically drought affected regularly. The district occupies the southern part of the State and is bounded on the north by Bellary district of Karnataka State and Kurnool district of Andhra Pradesh, on the 
East by Kadapa and Chittoor districts of Andhra Pradesh and on the South and West by the state of Karnataka. The district lies between $13^{\circ} 40^{\prime}$ and $16^{\circ} 15^{\prime}$ North latitudes and between $70^{\circ} 50^{\prime}$ and $78^{\circ} 38^{\prime}$ East longitudes. The location of the Anantapuramu District is shown in Figure 1. The total geographical area of the district is 19,197sq.kms. Rainfall defines the climate of the district. Southwest monsoon is the principal source of rainfall in the district. The maximum monthly rainfall was observed during the months of September and August was 128.6 and $101.8 \mathrm{~mm}$ respectively. Monsoon rainfall (June to December) contributes $86.15 \%(516.7 \mathrm{~mm})$ of the total rainfall $(599.8 \mathrm{~mm})$. The mean maximum temperatures upto $39.5^{\circ} \mathrm{C}$ during the month of April and $39.0^{\circ} \mathrm{C}$ during the month of May were observed. The mean minimum temperatures varied from $16.5^{\circ} \mathrm{C}$ to $25.5^{\circ} \mathrm{C}$. The wind velocities were highest during the month of June $(17.6 \mathrm{kmph})$ and lowest in the month of October $(5.8 \mathrm{kmph})$. The maximum sunshine hours observed during the month of March (10.00hrs) and minimum during the month of July (5.01hours). This phenomenon affects very notably the agricultural activities in this region and this is the main reason for selecting Anantapuramu for this study.

The map was geo-referenced with the help of SOI toposheets of the district. Figure 1 shows the block boundaries and raingauge stations surrounding Anantapuramu district which was generated using Arc View GIS software. The coordinates of the five stations are given in Table 1.

\section{Materials and Methods}

The methodology presented in this study and applied to the Anantapuramu district consisted of raingauge data, calculation of mean areal rainfall rainfall data, estimation of regional representative of SPI values using mean areal rainfall, calculation of the SPI values for each rainfall for multiple timescales, analysis of the temporal characteristics of droughts in the Anantapuramu using regional representative of SPI values. Further, the probability of change in four drought categories (D1, D2, D3, and D4) and the persistence of drought using a transition probability approach were evaluated.

The procedure followed for computation of SPI as follows (Guttman, 1999):

First, a probability density function that describes the long-term time series of rainfall observations is determined.

The base time of rainfall observation series can be any, depending on the time scale of interest. In the present study, running series of total precipitation corresponding to 1 month, 6-months, and 12-months were used and as result the corresponding SPIs were calculated: SPI-1, SPI-6, and SPI-12.

Once the probability density function is determined, the cumulative probability of an observed precipitation amount is computed.

The inverse normal (Gaussian) function, with mean zero and variance one, is then applied to the cumulative probability distribution function, which results in SPI.

SPI at different time scales, e.g. 1- or 3-month SPI of a particular month represents deviation in precipitation totals for the same month and current plus previous two months, respectively.

Positive values indicate greater than mean precipitation and negative values indicate less than mean precipitation.

The gamma distribution is defined by its probability density function is 


$$
g(X)=\frac{1}{\beta^{\alpha} \Gamma \alpha} x^{\alpha-1} e^{-x / \beta} \text { for } x>0 \text { (1) }
$$

Where $\alpha>0$ is a shape factor, $\beta>0$ is a scale factor, and $x>0$ is the amount of precipitation.

$\Gamma(\alpha)$ is the gamma function which is defined as

$\Gamma(\alpha)=\int_{0}^{\infty} y^{\propto-1} e^{-y} d y$

Fitting the distribution to the data requires that $\alpha$ and $\beta$ be estimated. Edwards and McKee (1997) suggested a method for estimating these parameters using the maximum likelihood approximations of Thom (1958) as follows:

$\alpha=\frac{1}{4 A}\left(1+\sqrt{1+\frac{4 A}{3}}\right)$

$\beta=\frac{\bar{x}}{\alpha}(4)$

Where,

$A=\operatorname{In}(\bar{x})-\frac{\sum \operatorname{In}(x)}{n}$

For $\mathrm{n}$ is an observation

The resulting parameters are then used to find the cumulative probability of an observed rainfall event for the given month or any other time scale

$G(X)=\int_{0}^{x} g(X) d x=\frac{1}{\beta^{\alpha} * \Gamma(\alpha)} \int_{0}^{x} x^{\alpha-1} e^{-x / \beta} d x$

Substituting $\mathrm{t}$ for $x / \beta$ reduces the above equation to incomplete gamma function

$G(X)=\frac{1}{\Gamma(\alpha)} \int_{0}^{\infty} t^{\alpha-1} e^{-t} d t$

Since the gamma function is undefined for $\mathrm{x}=$ 0 and a precipitation distribution may contain zeros, the cumulative probability becomes:
$H(X)=q+(1-q) G(x)(8)$

Where $\mathrm{q}$ is the probability of zero precipitation. If $\mathrm{m}$ is the number of zeros in a rainfall time series, q can be estimated by $\mathrm{m} / \mathrm{n}$. In this analysis, a small amount of rainfall was substituted for zero rainfall for each grid. This substitution does not affect the distribution of precipitation. For larger time scales (like 1, 3-, 6-, 9-, 12-months) the probability of monthly null precipitation is zero. So the errors in calculating the parameters $\alpha$ and $\beta$ due to the monthly null precipitation does not affect the distribution at larger time scales.

The cumulative probability, $\mathrm{H}(\mathrm{x})$, is then transformed to the standard normal random variable $\mathrm{Z}$ with a mean of zero and a variance of one, which is the value of SPI.

Following Edwards and McKee (1997) and Hughes and Saunders (2002), an approximate conversion is employed in this study, as provided by Abramowitz and Stegun (1965).

For lower range of cumulative probability (i.e., $0<\mathrm{H}(\mathrm{x}) \leq 0.5)$.

$Z=S P I=-\left(t-\frac{\left(C_{0}+c_{1} t+C_{2} t^{2}\right)}{\left(1+d_{1} t+d_{2} t^{2}+d_{2} t^{3)}\right.}\right)$

Where

$t=\sqrt{\left(\ln \frac{1}{(H(x))^{2}}\right)}$

For higher range of cumulative probability (i.e., $0.5<\mathrm{H}(\mathrm{x})<1$ )

$Z=S P I=-\left(t-\frac{\left(c_{0}+c_{1} t+c_{2} t^{2}\right)}{\left(1+d_{1} t+d_{2} t^{2}+d_{m} t^{3)}\right.}\right)$

Where

$t=\sqrt{\left(\ln \frac{1}{(1-H(x))^{2}}\right)}$ 


$$
\begin{array}{ll}
\mathrm{C}_{0}=2.515517 ; & \mathrm{C}_{1}=0.802853 ; \\
\mathrm{C}_{2}=0.010328 & \\
\mathrm{~d}_{1}=2.515517 ; & \mathrm{d}_{2}=0.802853 \\
\mathrm{~d}_{3}=0.010328 &
\end{array}
$$

Drought intensity classification into various categories with different values of SPI is given in the following Table 2. Positive SPI values indicate greater than median precipitation, and negative values indicate less than median precipitation.

\section{Results and Discussion}

The study produced the maps of drought severity at 1, 6 and 12 months time steps, in the Anantapuramu district of Andhra Pradesh, India. Figure 2-6 shows SPI values for three different time scales namely 3 months, 6 months and 12 months for the five stations.

The results show that the maximum SPI value $(-2.43)$ is for 6 months timescale in the year 2016 and for 1 and 12 months time scale the SPI value is maximum in the year 2007 ($0.91)$ and 2004 (-2.14) respectively for Anantapuramu mandal as shown in Figure 2. The results show that the maximum SPI value
$(-2.10)$ is for 6 months timescale in the year 2003 and for 1 and 12 months time scale the SPI value is maximum in the year 1990 ($0.34)$ and (-1.39) respectively for Atmakur mandal as shown in Figure 3. The results show that the maximum SPI value $(-1.83)$ is for 6 months timescale in the year 1988 and for 1 and 12 months time scale the SPI value is maximum in the year $1988(-0.97)$ and 2014 (-1.61) respectively for B.K Samudram mandal as shown in Figure 4. The results show that the maximum SPI value $(-1.83)$ is for 6 months timescale in the year 1988 and for 1 and 12 months time scale the SPI value is maximum in the year $1988(-0.62)$ and 2003 $(-2.92)$ respectively for Garladinne mandal as shown in Figure 5. The results show that the maximum SPI value (-2.71) is for 6 months timescale in the year 1995 and for 1 and 12 months time scale the SPI value is maximum in the year $2009(-1.83)$ and $1991(-2.96)$ respectively for Kudair mandal as shown in Figure 6. The drought occurrences were calculated based on percentage occurrence of each event (within each category) for each station with respect to total number of observations over the study area in the same category and timescale. Table 3 shows percentage of drought occurrence at multiple time scales and drought categories in Stations.

Fig.1 Location of the study area (Anantapuramu)

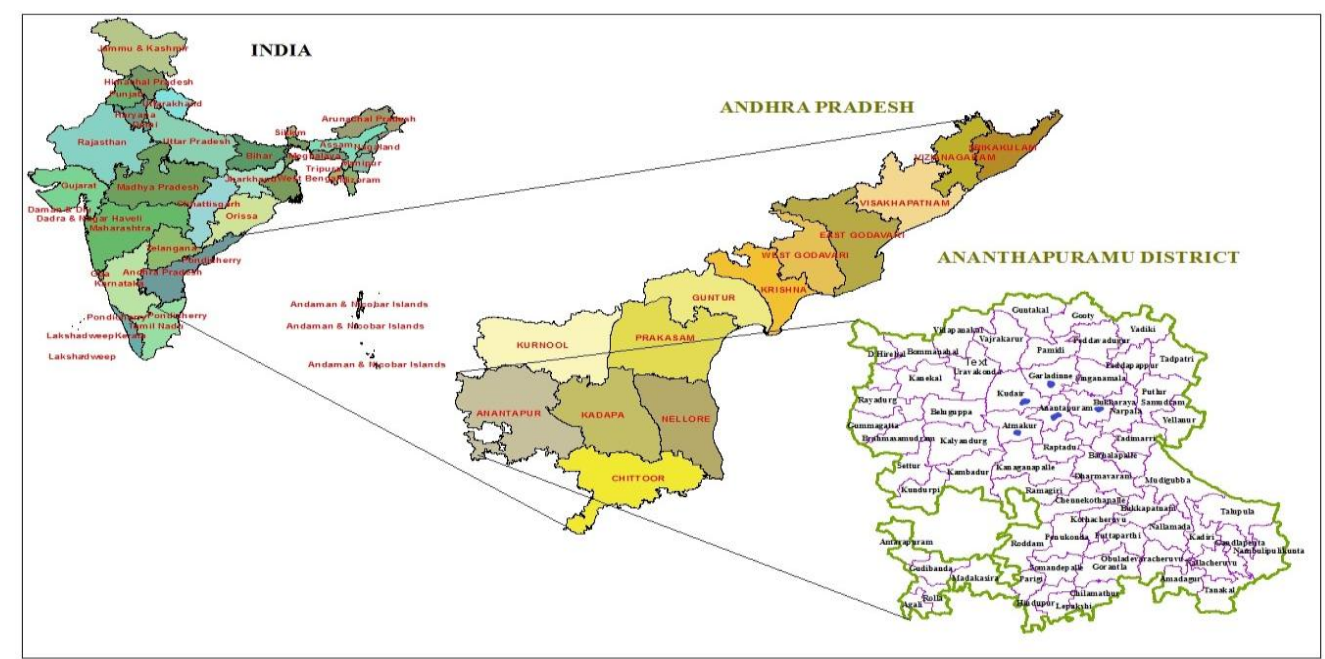


Fig.2 Variation of SPI for the Anantapuramu (1988-2017)

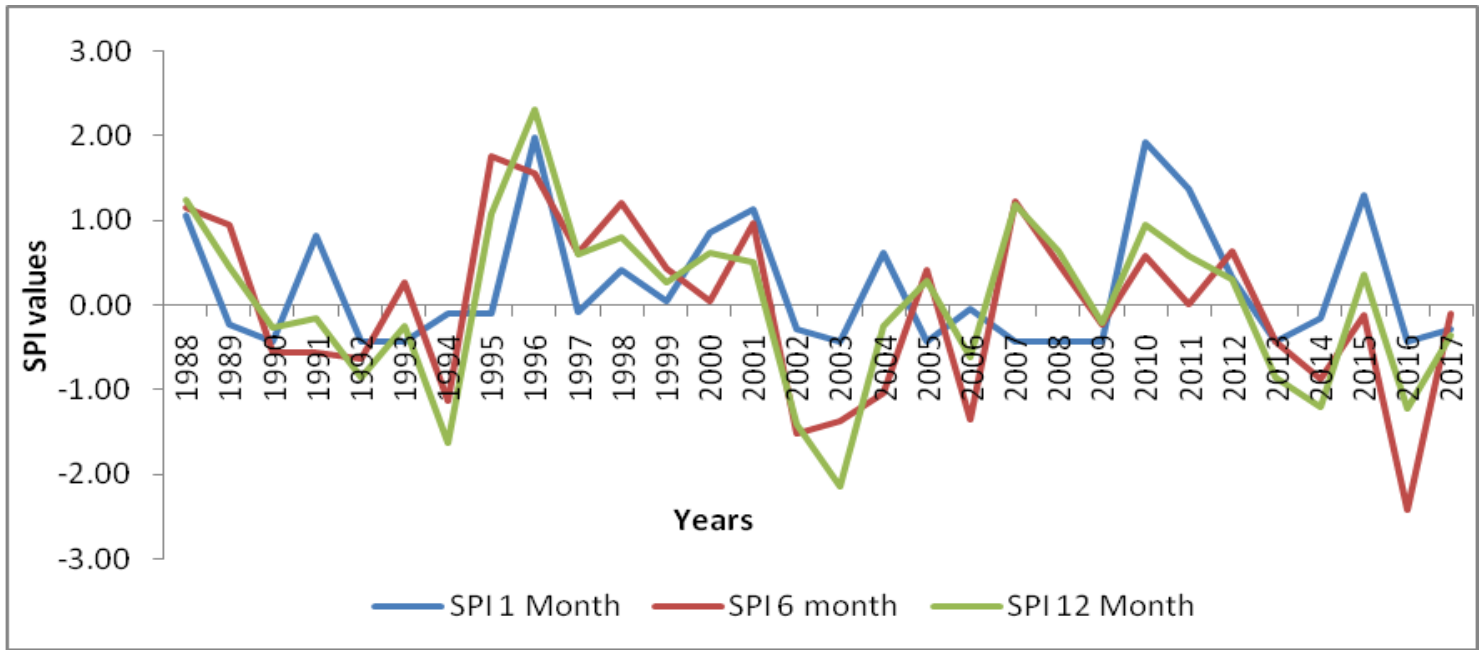

Fig.3 Variation of SPI for the Atmakur (1988-2017)

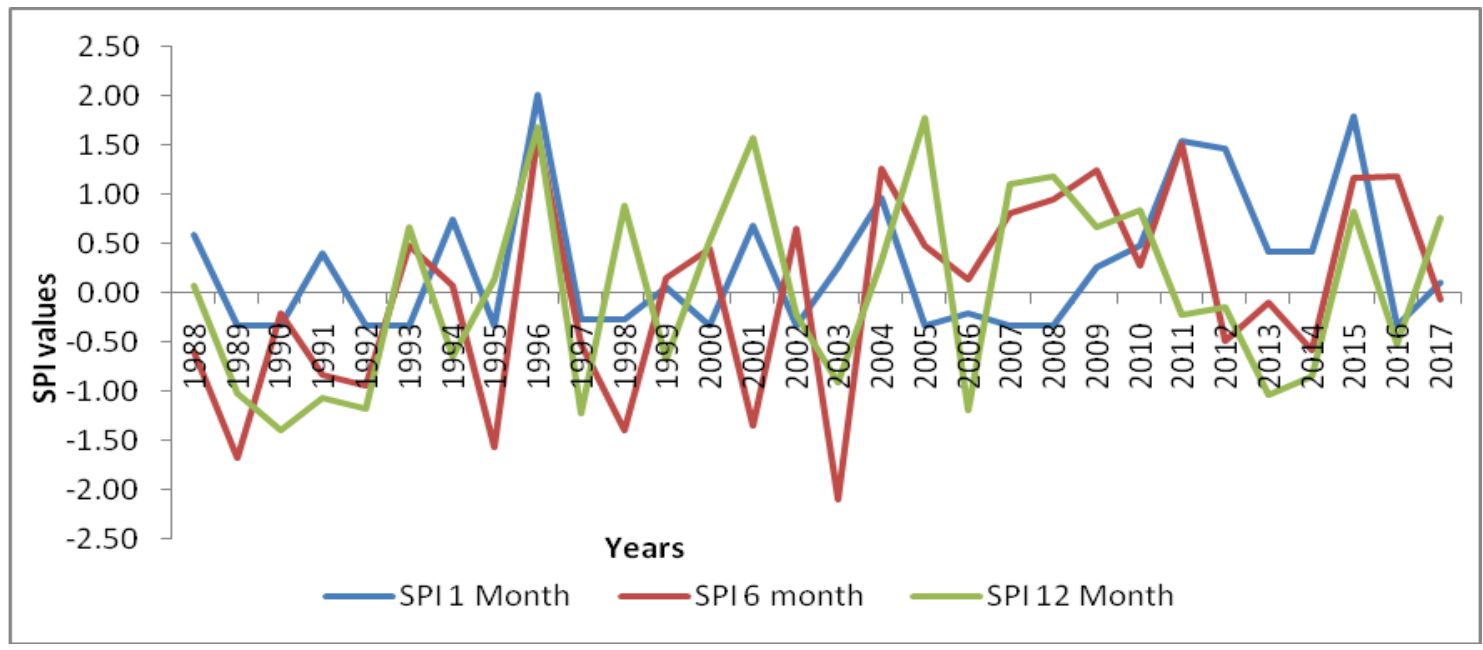

Fig.4 Variation of SPI for the B.K Samudram mandal (1988-2017)

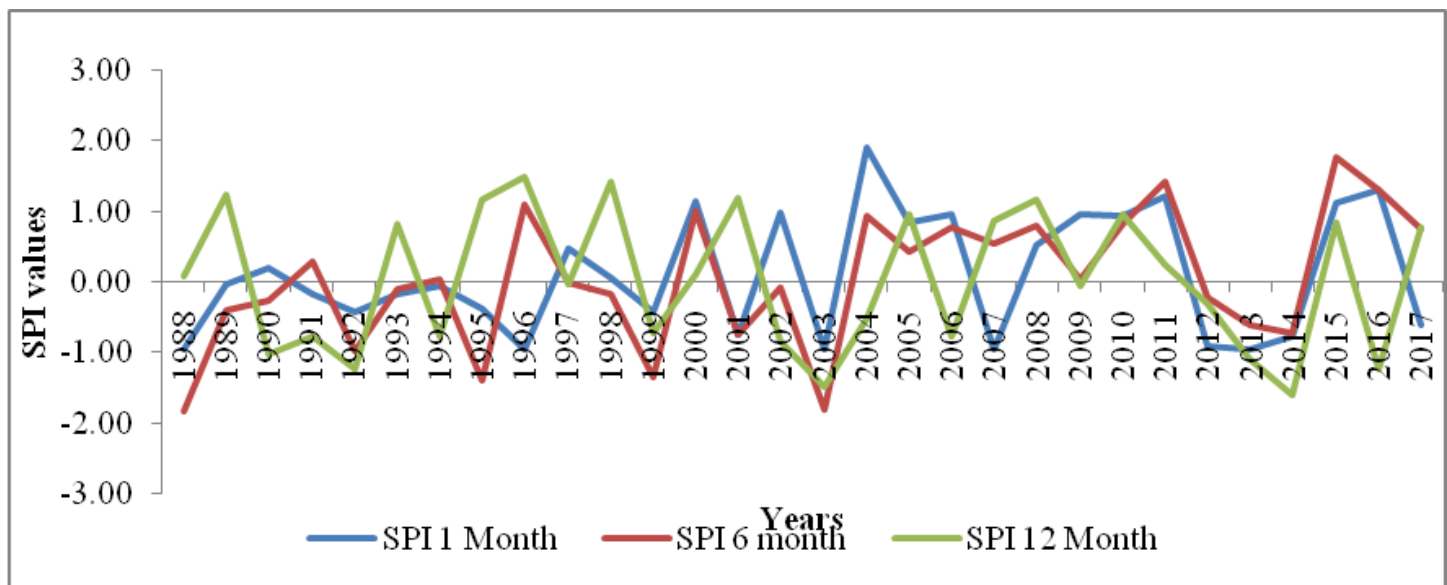


Fig.5 Variation of SPI for the Garladinne (1988-2017)

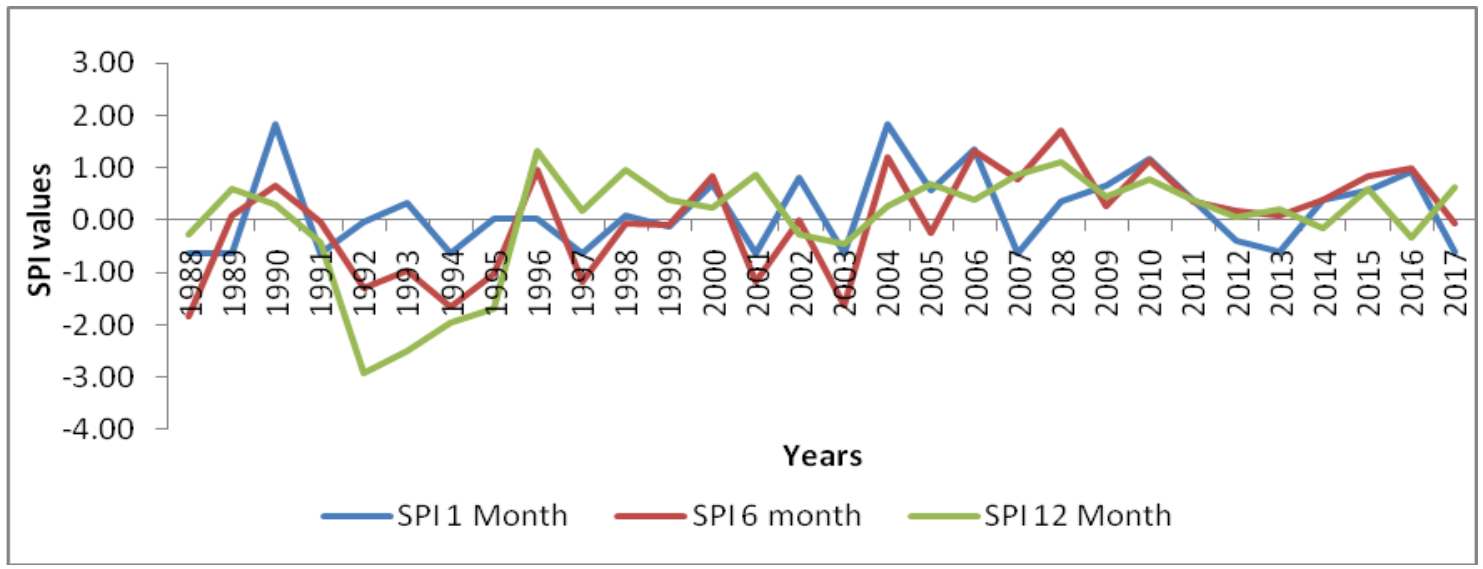

Fig.6 Variation of SPI for the Kudair (1988-2017)

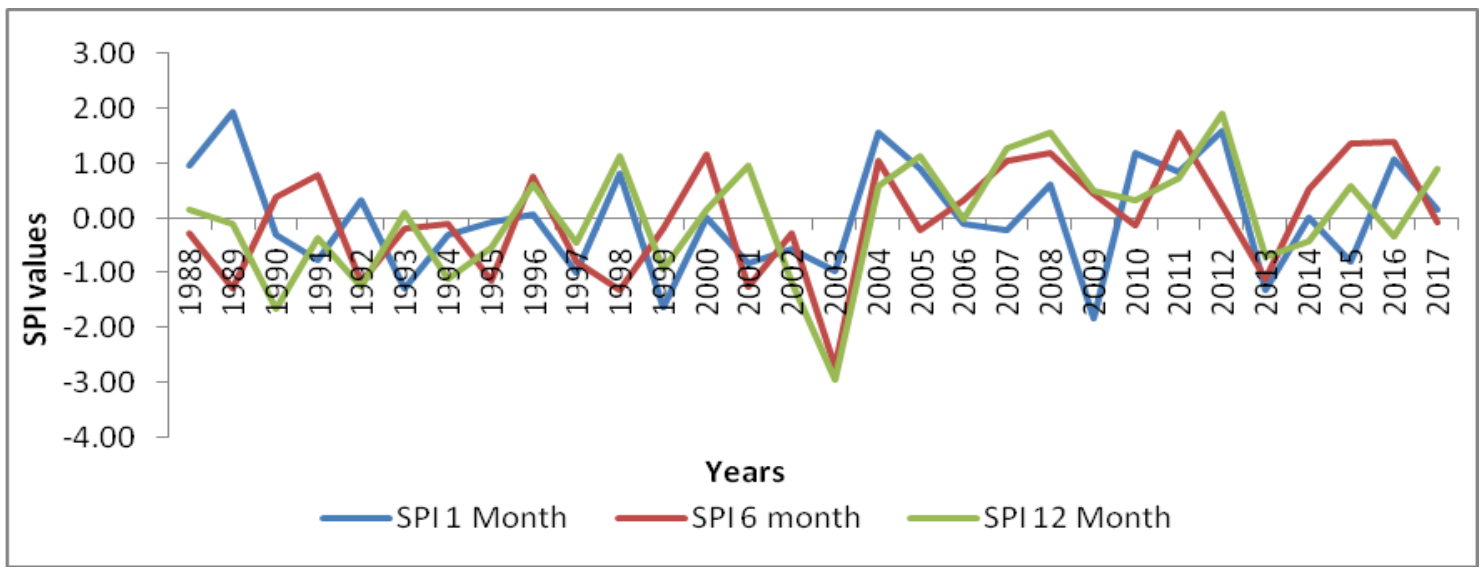

Table.1 Location of the raingauge stations

\begin{tabular}{|c|l|c|c|}
\hline S. No & \multicolumn{1}{|c|}{ Mandals } & Lattitude & Longitude \\
\hline $\mathbf{1}$ & Anantapuramu & $14^{\circ}-40^{\prime}-54^{\prime \prime}$ & $77^{\circ}-36^{\prime}-44^{\prime \prime}$ \\
\hline $\mathbf{2}$ & Atmakuru & $14^{\circ}-38^{\prime}-42^{\prime \prime}$ & $77^{\circ}-21^{\prime}-52^{\prime \prime}$ \\
\hline $\mathbf{3}$ & B.K Samudram & $14^{\circ}-41^{\prime}-31^{\prime \prime}$ & $77^{\circ}-38^{\prime}-08^{\prime \prime}$ \\
\hline $\mathbf{4}$ & Garladinne & $14^{\circ}-48^{\prime}-51^{\prime \prime}$ & $77^{\circ}-35^{\prime}-51^{\prime \prime}$ \\
\hline $\mathbf{5}$ & Kudair & $14^{\circ}-43^{\prime}-53^{\prime \prime}$ & $77^{\circ}-26^{\prime}-21^{\prime \prime}$ \\
\hline
\end{tabular}

Table.2 Classification of drought intensities based on SPI

\begin{tabular}{|c|}
\hline SPI values \\
\hline 0 to -0.99 \\
\hline-1.0 to -1.49 \\
\hline-1.5 to -1.99 \\
\hline$<-2$ \\
\hline
\end{tabular}

\section{Drought category}

Mild drought (D1)

Moderate drought (D2)

Severe drought (D3)

Extreme drought (D4) 
Table.3 Occurrences of drought categories (percentage)

\begin{tabular}{|c|c|c|c|c|}
\hline \multirow{2}{*}{ Station } & \multirow[t]{2}{*}{ Drought category } & \multicolumn{3}{|c|}{ Drought occurrences (\%) } \\
\hline & & SPI - 1 & SPI - 6 & SPI - 12 \\
\hline \multirow[t]{5}{*}{ Anantapuram } & Extreme $(\leq-2)$ & 0.00 & 3.33 & 3.33 \\
\hline & Severe(-1.5 to -1.99$)$ & 0.00 & 3.33 & 3.33 \\
\hline & Moderate(-1 to -1.49$)$ & 0.00 & 13.33 & 10.00 \\
\hline & Milld(0 to -0.99$)$ & 60.00 & 26.67 & 30.00 \\
\hline & & 60.00 & 46.67 & 46.67 \\
\hline \multirow[t]{5}{*}{ Atmakur } & Extreme $(\leq-2)$ & 0.00 & 3.33 & 0.00 \\
\hline & Severe(-1.5 to -1.99$)$ & 0.00 & 6.67 & 0.00 \\
\hline & Moderate(-1 to -1.49$)$ & 0.00 & 6.67 & 23.33 \\
\hline & Milld(0 to -0.99$)$ & 46.67 & 26.67 & 26.67 \\
\hline & & 46.67 & 43.33 & 50.00 \\
\hline \multirow[t]{5}{*}{ B.K Samudram } & Extreme $(\leq-2)$ & 0.00 & 0.00 & 0.00 \\
\hline & Severe(-1.5 to -1.99$)$ & 0.00 & 3.33 & 3.33 \\
\hline & Moderate(-1 to -1.49$)$ & 0.00 & 6.67 & 13.33 \\
\hline & Milld(0 to -0.99$)$ & 50.00 & 36.67 & 30.00 \\
\hline & & 50.00 & 46.67 & 46.67 \\
\hline \multirow[t]{5}{*}{ Garladinne } & Extreme $(\leq-2)$ & 0.00 & 0.00 & 6.67 \\
\hline & Severe(-1.5 to -1.99$)$ & 0.00 & 10.00 & 6.67 \\
\hline & Moderate(-1 to -1.49$)$ & 0.00 & 13.33 & 0.00 \\
\hline & Milld(0 to -0.99$)$ & 40.00 & 20.00 & 16.67 \\
\hline & & 40.00 & 43.33 & 30.00 \\
\hline \multirow[t]{5}{*}{ Kudair } & Extreme $(\leq-2)$ & 0.00 & 3.33 & 3.33 \\
\hline & Severe(-1.5 to -1.99$)$ & 6.67 & 0.00 & 3.33 \\
\hline & Moderate( -1 to -1.49$)$ & 6.67 & 20.00 & 10.00 \\
\hline & Milld(0 to -0.99$)$ & 40.00 & 30.00 & 30.00 \\
\hline & & 53.33 & 53.33 & 46.67 \\
\hline
\end{tabular}

Figures 2-6 represents and observed that drought frequency changes as discussed. At the shorter time scale SPI-1, drought frequency increases but its duration decreases and ends for shorter periods.

At the medium time scale SPI-6, drought frequency is less when compared to short term drought. On longer time scales SPI-12, drought becomes less frequent but lasts longer. Analysis of the computed SPI series shows the division has experienced droughts in term of severity and duration is observed during 1988, 1990, 2000 and 2010 particularly in the years 1988, 1999, 2003 and 2014 were observed as worst drought years.

The analysis of temporal SPI from rainfall data is useful to determine the spatial distribution and characteristics of drought in the Anantapuramu District, Andhra Pradesh, India. To generate drought severity for the different time scales and months of the year. Temporal SPI graphs show that the maximum SPI value (extreme drought) occurs in station 5 in the year Analysis of the computed SPI series shows the stations has experienced droughts in term of severity and duration is 
observed during 1988, 1990, 2000 and 2010 particularly in the years 1988, 1999, 2003 and 2014 were observed as worst drought years. Mild and moderate droughts occur in the central portion of the study area. The northeast part of the study area is prone for severe drought and extreme drought occurs in northwest and southwest part of the study area. It is found that SPI is a good indicator of the drought characteristics like severity. There exists no relation between the droughts of short and longer time scales as well as among the severity classes of each time period.

\section{References}

Guttman, N.B. 1999. Accepting the standardized precipitation index: a calculation algorithm. J. Am. Water Resour. Assoc. 35 (2): 311-322.

McKee, T.B., Doesken, N.J. and Kleist, J. 1993. The relationship of drought frequency and duration to time scales. In: Proceeding of the 8th Conference on Applied Climatology, American meteorological society, Boston. pp. 179-184.

Nareshkumar, M., Murthy, C.S., Seshesai, M.V.R and Roy, P.S. 2009. On the use of Standardized Precipitation Index (SPI) for drought intensity assessment. Meteorological applications. 16:381389.

Pai, D.S., Sridhar, L., Guhathakurta, P and Hatwar, H. R. 2011. District-wide drought climatology of the southwest monsoon season over India based on standardized precipitation index (SPI). Natural Hazards. 59: 1797-1813.

Yldz, O. 2009. Assessing temporal and spatial characteristics of droughts in the Hirfanli dam basin. Turkey Scientific Research and Essays. 4 (4): 49 - 255.

\section{How to cite this article:}

Uma Bai, D., B. Sarojini Devi, H.V. Hema Kumar and Sumathi, P. 2018. Assessing Temporal Characteristics of Meteorological Drought Trends in the Anantapuramu District, Andhra Pradesh. Int.J.Curr.Microbiol.App.Sci. 7(08): 1525-1533. doi: https://doi.org/10.20546/ijcmas.2018.708.174 